\title{
The Core Critical Areas for Innovation to Sustain Business Growth: Management Implications and Business Outputs
}

\author{
Article by Abena Pokuaa Ackah \\ Management Consultant, Accra/Ghana \\ E-mail: ackahabena@yahoo.com / ackahabena61@gmail.com
}

\begin{abstract}
In an age of increasing dependence on new trends and ideas, innovation has become a critical conduit for the thrust of business growth. Also, technological advancement and its rapid accompanying challenges of similar products and services make it indispensably necessary to create new ideas to facilitate the development or augmentation of new/existing products, services, processes, and procedures to sustain business growth.

This article examines the varying views on types of business innovation; eliciting the key concepts underpinning these viewpoints, and argues that the areas for business innovation espoused by the different proponents are dispersal and lack precise focus. The article further establishes that innovative approach to promote business growth ought to be simplistic and clear in focus. It posits innovation in the construct of the core business functions - product delivery, service delivery, process delivery and people delivery for which; the author names as 'The 4Ds of Innovation' and stipulates that these are the fundamental elements underpinning the promotion of business growth. The author further argues that a business entity can maximize its business growth if innovative activities were specifically directed in these critical areas.

The paper provides a conceptual framework for innovative activities as well as innovation audit matrix to monitor innovative activities within the organizational setup; suggesting a more simplistic approach that ensures continuous focus on the core critical areas, and bringing in management logic interventions to stimulate innovation and promote business growth.
\end{abstract}

Keywords: core, critical areas, innovation, business growth, strategic outputs, and management implications.

\section{Introduction}

Innovation is defined in Thesaurus Dictionary using many synonyms such as: "breaking new ground, leading -edge, state-of-the-art, contemporary, imaginative and creative". This overtly connotes that innovation is about creativity and ideas. Innovation is further explained as "the process of translating an idea or invention into a good or service that creates value for which customer will pay" (www.business dictionary.com). This suggests that innovation only happens when an idea is transformed from a conceptual stage to commoditization. Specifically, the idea must be transformed into product or service to satisfy a precise need or want to attract an economic cost. Howard and Sheth (1969) quoted by Popa I. L et al (2010) define innovation as any new element brought to the buyer, which may not be necessarily new to the organization. The emphasis is on the ability of the organization to transform an idea into the state of economic value (product/service) where it is made available to the buyer. The product could either be a new product introduced into the market or an existing product.

Business Council Australia (1993) interprets innovation as an adoption of new or significantly improved elements to create added value to the organization directly or indirectly to its customers. Other conceptual definitions have been espoused by Drucker (1954), who postulates that the two basic functions of any organization are marketing and innovation and suggests that innovation is the thrust for technology-based business. In other words, innovation is one of the key critical functions to propel a business to develop technologically based products and services. Boer and during (1993) quoted in Popa L.I et al (2010) have 
a similar perspective that innovation underpins the development of technologically based products in an organization.

All these conceptual definitions speak to creativity and ideas as the bedrock to advance innovative activities within the organizational settings to produce results. But creative thinking is a process that generates ideas and this can only materialize in a tranquil and conducive environment for which; an organization creates through good interrelationship with colleagues, knowledge and learning, consistency and focus, and ability to revamp unusable ideas. Amabile (1998), upholds this view and suggests that creative thinking can happen under specific conditions such as:

- Comfortably disagreeing with others and trying other methods of solutions that are different from the current situation.

- Ability to combine knowledge from previous criticized work.

- Perseverance through challenging problems and negative influences

- Ability to recline, meditate on your efforts and get back to it with fresh perspectives.

This article seeks to throw light on different types of innovation and posits the concept of innovation to encapsulate four critical areas to sustain business growth. It propounds a model for innovation that is simplistic and more focused to deal with the core business areas; and provides a framework for continuous innovation to sustain business growth.

\section{Literature review}

\section{The theory of innovation}

The concept of innovation has seemingly obtained a greater acceptability and desirability over the years. However, the reality of an attempt to implement innovation in most organizations are either shot down or met with great reluctance because every innovation is characterized by a change, which comes with accompanying challenges (Hobcraft 2015). In the past, innovation was focused on only products; services and other critical areas in business were ignored by the proponents. However, innovation in recent times has been seen in a wider perspective to cover a wider spectrum of business areas than before giving rise to diverse interpretations to types of innovation.

Many proponents have provided different types of innovation for business growth. One of these types of innovation is the framework by Elmansy (2015) which reflects the innermost workings of the organization and settles on ten critical areas in innovation as profit-model, network, structure, process, product performance, product system, and service, channel, and brand innovations. The framework addresses all issues within the business, but it is, however, large in scope and does not allow simplistic understanding of innovation construct to sustain business growth.

There is an incremental innovation which is characterized by fewer risk opportunities for business growth. It is seemingly focused on small improvements to company's products/services/methods that are done incrementally (www.incrementalinnovation.com). This type of innovation distinguishes incremental improvements from radical improvements. It excludes the recognition of people as one of the critical areas in business that needs continuous improvements and therefore renders it limited in scope. There is also disruptive innovation introduced by Christensen (1995) which suggests that companies that tend to innovate faster than their customer needs turn out to be complicated, sophisticated and expensive for their customers. Disruptive innovation can be attributed to leaders with clouded vision who lack well-defined problems to be solved and as such their innovative approaches tend to be swift, abrupt and disruptive to the business system and consequently results in poor performance. This type of innovation is quite synonymous with structural innovation championed by Howells (2011) which model seeks to give a seemingly unified perspective to innovation, but it does not seek to improve methods of operations and the focus is diversional and disruptive. Such types of innovations are mostly carried out by leaders of organizations who seek out their own intentions and interests. 
There is also business model innovation which involves key decisions that jointly define how a business should earn its revenue, incurs its cost and manages its risks. Girotra and Neltesssine (2014) view business model innovation as changes to these key decisions and provide a framework that allows managers to take innovation to a level that is reliable and can be improved. The framework suggests four paths to business model innovation: (1) reduce risk by making changes to companies' mix of products or services, (2) focus narrowly which makes business model to be effective and unique to market segments, (3) share commonalities in components among different products, and (4) create investments across portfolios by selecting assortment of products or markets to reduce overall riskiness. Girotra and Neltesssine framework is clearly product/market-driven approach leaving out significant elemental areas such as people and processes, which are also areas in business that need constant innovation to propel business growth. The model does not encapsulate the core critical areas in business which makes it limited in scope.

The business model innovation lacks a proper framework and it is characterized by a change which comes with accompanying challenges and therefore necessitates the application of change management principles to which; if not applied properly innovation is bound to fail. Although innovation can be seen to be rooted in the system of change; the change element cannot be the fulcrum for innovation and therefore renders the model limited in scope and lacks further exploration of opportunities to maximize the effect of innovation.

\section{Moore's model of innovation}

Another alternative framework for innovation has been espoused by Moore (2015). He suggests ten areas for innovation: Disruptive, Application, Product, Platform, Line-extension, Enhancement, Marketing, Experimental, Value-engineering, Integration, Process, Value migration, Organic and Acquisition innovations. His framework focuses on the holistic workings of an organization and its business systems. He views these areas of business innovation in the context of product life cycle and suggests the movement of old products/services and methodologies of operations to new and newer perspectives as indicated:

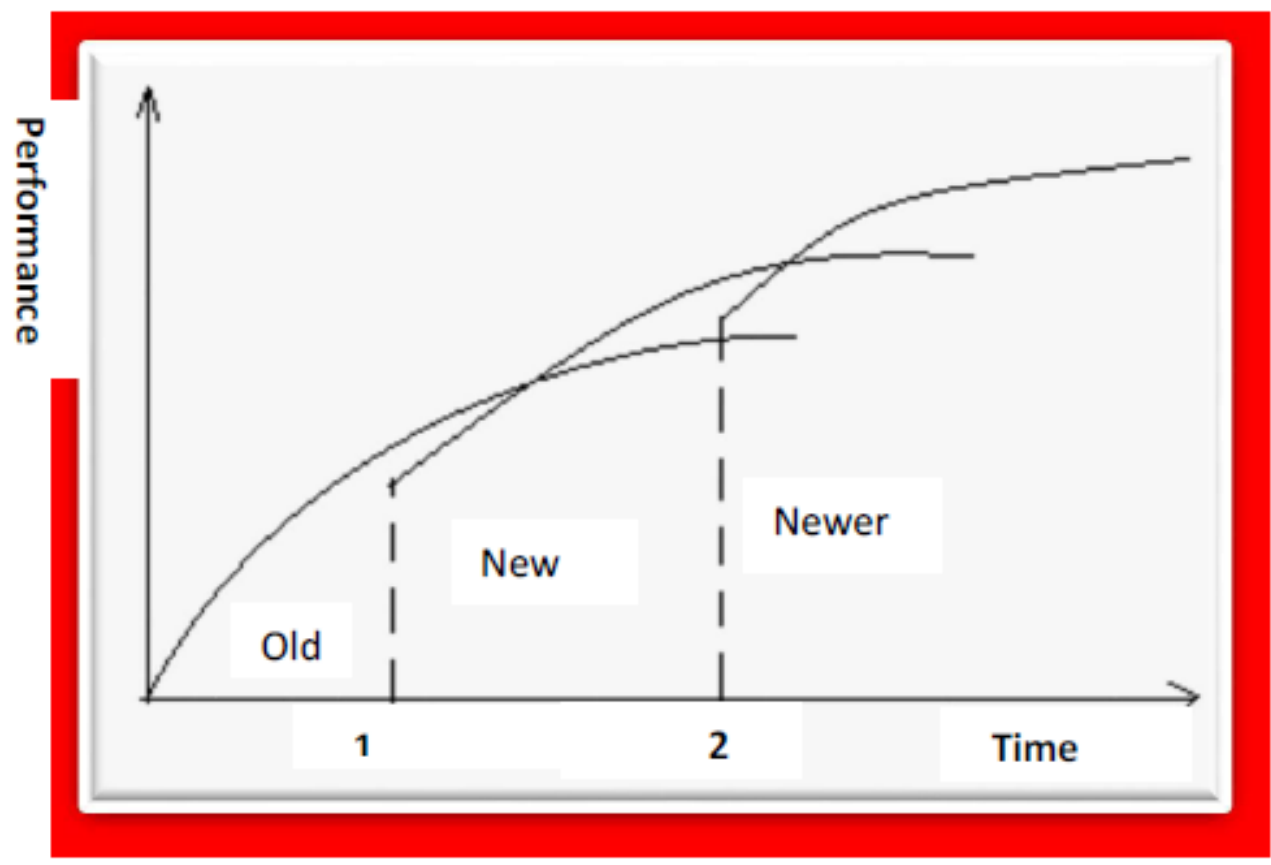

Figure 1. Moore's model of innovation

Source: adopted from Geoffrey A. Moore 
DOI: $10.21522 /$ TIJMG.2015.03.02.Art017

ISSN: $2520-310 \mathrm{X}$

Moore looks at these areas of innovation as having a life span to perform effectively. He suggests that every area of innovation will do well when its performance life cycle is recognized and innovative strategies are developed to transform these areas from old to new and newer forms in accordance with its stage of performance and time. Though Moore's concept of innovation relies on the product life cycle concept which is quite realistic, it is obviously large in scope and not streamlined enough to elicit a simplistic understanding and approach to innovation to stimulate business growth. It also eludes the stage where products/services or methods may not be necessarily transformed from old to new or newer but may be significantly improved. Also, it does not include people as the nerve centre for promoting innovation in the organizational setup.

In as much as we agree with the diversity of interpretations to types of innovation in business, these types of innovation are either dispersal or limited in scope and do not provide a comprehensible focus for innovative activities. The perspectives are devoid of clear simplistic approach that gives a clearer focus to stimulate business growth. Precisely, innovation should be seen to target key areas in the business to produce positive results. The varying interpretations of innovation concepts must be simplistic enough to stimulate business growth.

Based on the theoretical arguments above, we introduce a conceptual framework which is more simplistic and focused and we believe that they are the core critical areas needed for effective innovation. These areas are People Delivery Innovation, Process Delivery Innovation, Product Delivery Innovation, and Service Delivery Innovation for which; we have named as the 4DS OF INNOVATION as indicated below:

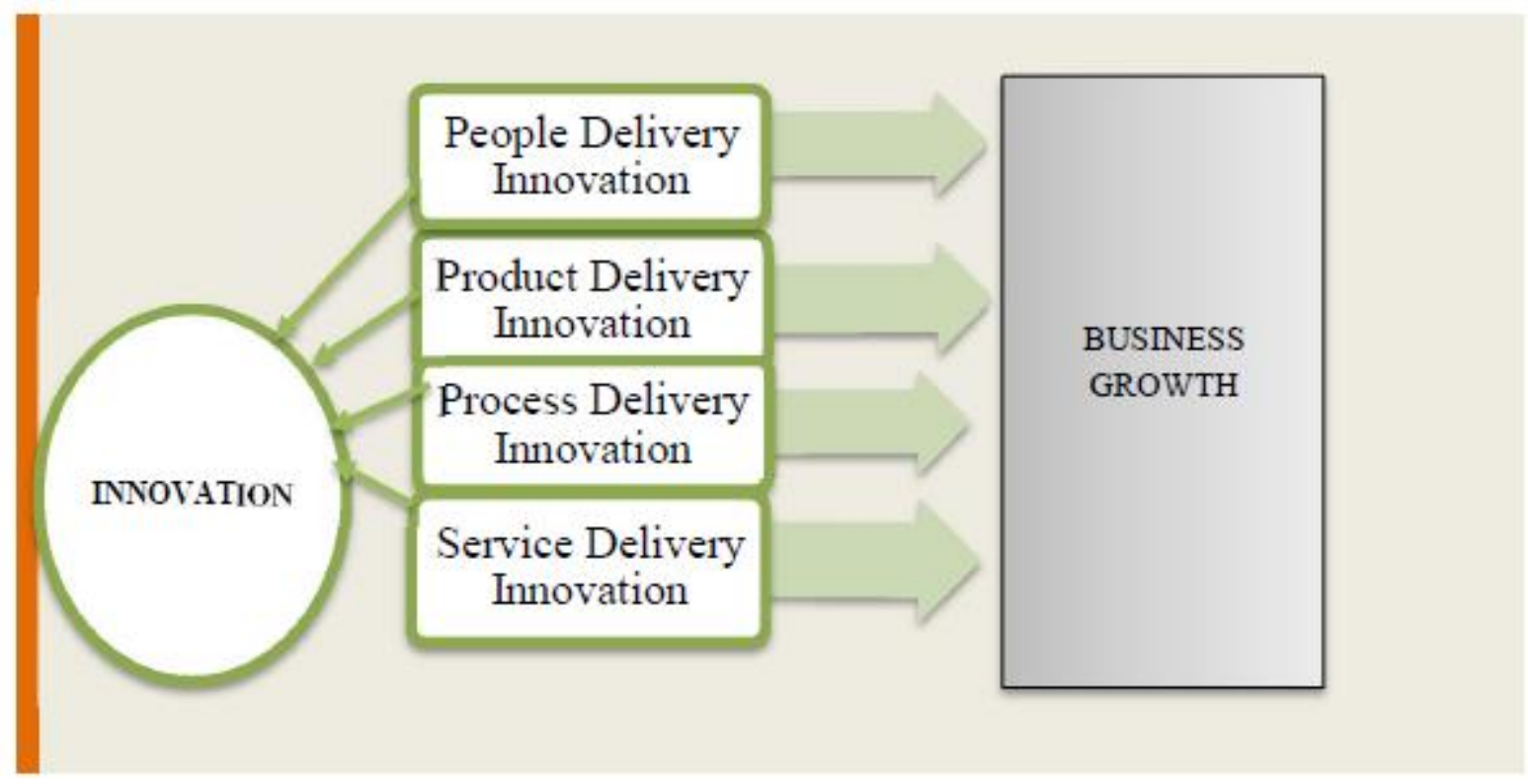

Figure 2. Conceptual framework: the 4ds of innovation

The emphasis of this model is on four core critical areas in business upon which all types of innovation may be derived. Innovation in its simplistic understanding is where new or improved products/services or methods are introduced and the 4Ds of innovation are the key drivers that sum up the innermost workings of the business which any innovation should focus to create a competitive advantage for the organization. The 4Ds of innovation to sustain business growth is explained:

\section{People delivery innovation}

\section{a. Top management commitment}


People represent the tool for innovation in an organization (Camerli et al., 2006) and people delivery innovation signifies everything to do with the people in an organization. It looks at the human resource within the organization stretching from the top management to the bottom staff. Liopis (2014) recognizes the importance of people to bring about innovation and projects two types of persons needed to stimulate innovative practices in the organization. According to him these persons inordinately seek possibilities that are interminable in pursuit to achieve desired results. In other words, the two types of persons are resultsoriented; fixated in the ambition to bring about change.

But, stimulating innovation in people resides in the commitment of leadership within the organization. Leaders that see employees as the drivers of innovation make it a priority to improve on structures, skills, functions, and roles etc. to enhance innovative activities in the organization. Mehregany (2013) expresses similar assertion that the type of people, structures, skills, roles, and functions you deliver stimulate innovative practices within an organization. He emphasizes that companies should go beyond the utilization of internal resources and capabilities and involve external resources to elicit ideas for innovation.

Popa et al (2010), express their conviction that any organization capable of releasing resources for innovative activities, promotes motivation to create an organizational climate for idea generation. Mehregany (2013) affirms the need for top management commitment to building knowledge, competencies and continuous training. He asserts that a firm with existing repository of intellectual

Capacity can generate more ideas, and that building of knowledge and innovations are harder to put in place and maintain. He asserts that a firm with an existing repository of intellectual capacity can generate more ideas towards building knowledge and innovations that are harder to sustain.

Vincent (2014) sees the importance of people in the innovation process and expresses that they are a critical conduit to stimulate innovation. He sees creativity as the tool for problem-solving and explains that it takes only a great skill and mindset of employees to introduce new and more efficient solutions. He asserts that it is, therefore, the collective skills of individuals that gives impetus to innovative solutions to respond to the need requirements of customers.

\section{b. Innovative leadership recognition}

Another perspective on the "people delivery innovation" is the ability to recognize an innovative leader in the organization. Recognizing innovative leader is very vital to the innovation process. Agbor (2008) affirms that leadership is the foundation and source of organizational extraction of creativity and innovation, and the need for employees to recognize the innovativeness in their leaders (Hobcraft 2015) is vital to sustain the innovation process.

Deschamps and Nelson (2014) point out tribal and cultural differences prevalent within an organization; which is characterized by its own beliefs, value systems and judgments; and the need for an organizational leader with a strong personality to cut across these potential barriers. Deschamps and Nelson further describe two types of innovative leaders; the front-end leader and the back-end innovative leader. They stipulate that the type of innovative leader can only emanate from their functional orientation, possible background disciplines and their general management interest and attitudes. The Significance is the employees' ability to strike the balance between these leaders in order to give impetus to innovative practices in the organization.

\section{Product delivery innovation}

This type of innovation is a direct response to the needs of customers. "A product innovation is the introduction of a good or service that is new or has significantly improved characteristics or intended purpose" (www.innovationpolicyplatform.org). Also, www.businessdiction.com describes product innovation as "The development and market introduction of a new and redesigned or substantially improved good or service". The definitions put emphasis on the product's features and benefits as the basis for product innovation. However, "product delivery innovation" goes beyond just the characteristics of the product and extends its scope to encompass the value chain of the introduction of the new product into the market, and its predictability of maintaining its success in the market. Therefore, the four main marketing mix strategies 
DOI: $10.21522 /$ TIJMG.2015.03.02.Art017

ISSN: $2520-310 \mathrm{X}$

- product, price, promotion and place (4ps) is the additional focus on the "product delivery innovation" which should continuously be improved to facilitate product success in the market.

When a new or significantly improved product is introduced into the market, clear objectives for the other marketing mix elements (price, promotion, and place) should be established to facilitate innovative solutions to the operations in order to achieve product success in the market. Shipulski (2014) supports this argument and stipulates that for every innovation to be successful there ought to be clarity of purpose. He reiterates that a new product innovation must clearly defines the customer outcomes; what are customers' expectations in product usage, the distribution channels available to customers, at what price it will be sold, and to what target market. These questions respond directly to the marketing mix elements (4ps) which ensures that the introduction of a new product into the market is successful.

This means that organization should come up with innovative pricing; promotion processes should be innovative enough to communicate product quality and benefits to the public; place (distribution network) that answers the how, when and where to take product must be innovative using the state-of-the-art technology to make the product accessible to all. As the methods of marketing mix elements get new or significantly improved; product delivery to the market assumes a substantial value to firm's product offering to create a competitive advantage.

\section{Process delivery innovation}

The process delivery innovation is to do with systems and methods of delivering an organization's offerings. Its focus is on the systemic value chain of the business which needs to be continuously improved as and when the need arises. Therefore, the "process delivery innovation" seeks to involve the total processes, procedures, structure, forms, and infrastructure from which the organization operates. The delivery of these systems needs to be significantly improved or introduction of new ways of operations and practices from time to time. This innovative approach will help the organization to develop competence to tackle all processes related to the business.

But, process delivery innovation can only be sustained if there are effective leadership and efficient structure in place. Steiner et al. (2014) affirm in their empirical research "Well suited Organization to Open Innovation: Empirical Evidence from an Empirical Deployment" that the organizational model adopted by a company underpins its performance and competitiveness. They opine that a better organic organizational structure will support innovative process than mechanic organizational structure. Agbor (2008) supports this view and emphasizes the need for effective institutional structures that constantly develop creative leaders to manage and sustain the innovative process.

\section{Service delivery innovation}

Service delivery innovation is focused on improving all aspects of the service delivery process in an organization. The differences between service delivery and process delivery are not clearly far apart seemingly may be synonymous if not explicitly defined. Indeed, service delivery innovation and process delivery innovation may be directly linked. However, the distinction between the two is that service delivery innovation relies on the combination of approaches and the people responsible to deliver the service with characteristics; whereas process delivery innovation is to do with new methods and forms, equipment and skills that deliver the service.

Dawson (2007) posits the success of a professional service firm in the continual improvement of service delivery methodologies to create a consistent increase in client value and profitability as well as cost reduction. Indeed, consistent delivery of service innovation plays a role in retaining customers (Neena et al. 2013), and fulfilling customers' needs which allow companies to demand higher prices for their market offering (Eggert et al. 2014). Service innovation, therefore, fortifies the competitiveness of a firm's positioning; stabilizes cash flows and protects the core business to generate additional revenues from sales and repeat purchase from both existing and new customers (Gebaner et al. 2011), (Jacob and Vlaga, 2008).

Top management must be committed to release and harness resources to improve the service delivery process which will undoubtedly improve service quality dimensions which are tangibility, reliability, 
responsiveness, assurance, and empathy. These are the bedrock of emitting service that is efficient and effective in character to achieve service that goes beyond desirability to exceed customer's expectation.

\section{Strategic framework for continuous innovation}

The strategic framework provides innovative structures to facilitate activities of the 4Ds of innovation within the organization to achieve its desired goals. It aims to provide the organization with guidelines that will stimulate and encourage effective innovative process as indicated below:

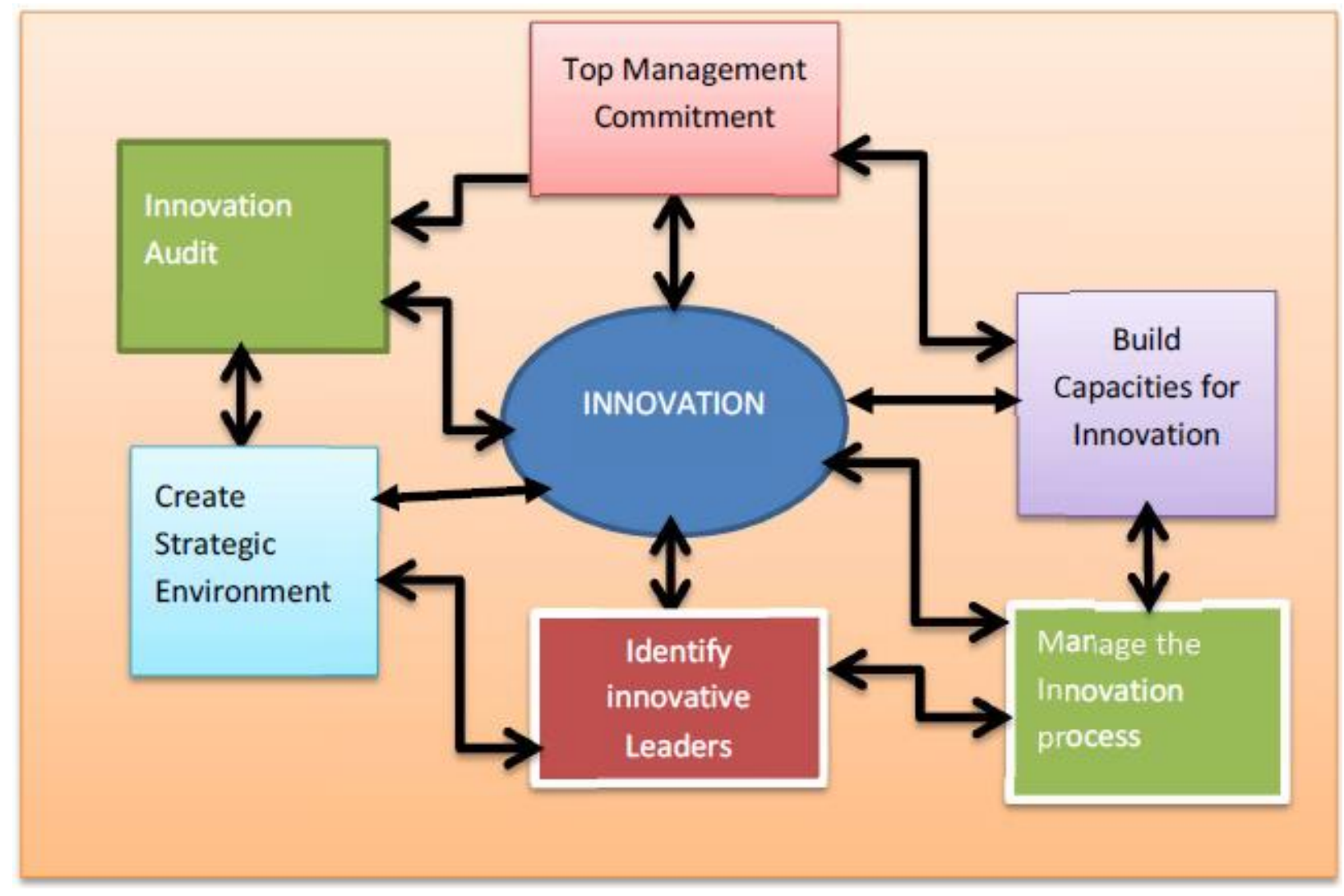

Figure 3. The framework for continuous innovation

\section{Top management commitment}

Every innovative organization must have the commitment from the top management where creative thinking and ideas receive many commendations and permit the ideas to nurture and advance from conceptualization stage into commercialization to attract monetary value. Top management with innovation orientation demonstrates a high level of encouragement to any innovative failures that emanate from the efforts of its employees and creates support systems that affirm top management's commitment to the innovative processes within the organization. Organization's ability to support innovative culture facilitate the innovative process (Hanna 2013), and that innovation comes out of individual's creativity, knowledge, and skills (Carmeli et al. 2006).

\section{Innovation audit}

Innovation audit is simply to assess the level of innovation in relation to the 4Ds and how the company can adopt innovation audit matrix to drive innovative activities as indicated: 
DOI: $10.21522 /$ TIJMG.2015.03.02.Art017

ISSN: $2520-310 \mathrm{X}$

Figure 4. Innovation audit matrix

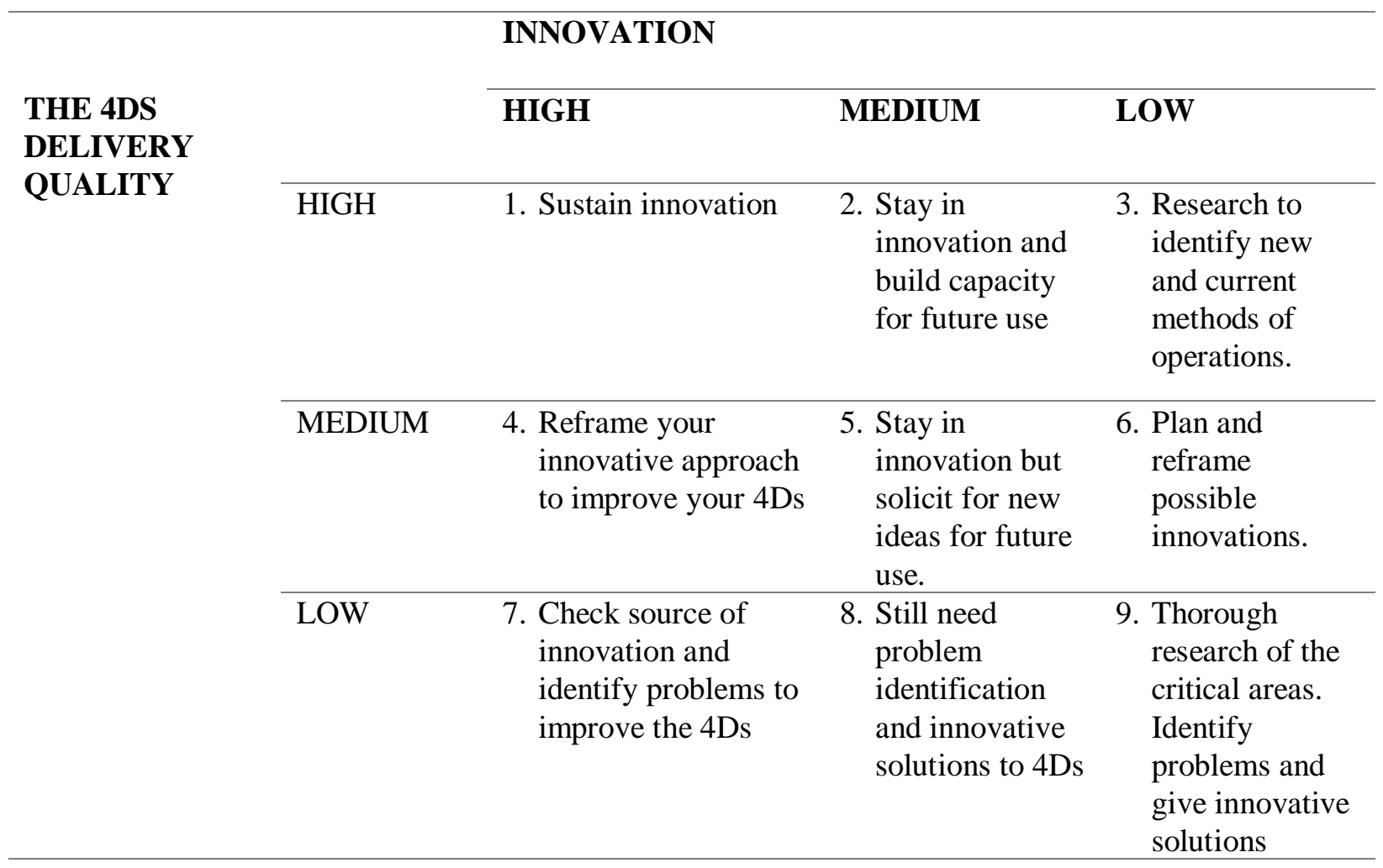

It is assumed that every aspect of the 4Ds that has been used over time in an organization will go through a life cycle process which requires re-engineering. For example, if an element of the 4Ds, has low quality and innovation is also low; the best option for such scenario is to identify problems in the critical areas and give innovative solutions. There is no need to wait without acting. You need to either act or do not act and face business catastrophe.

\section{Create strategic environment}

A sound environment should pre-exist in an organization to promote cohesion among identified innovative teams and leaders to pursue new strategic thinking and ideas to stimulate new innovations within the organization. The sound environment is also about good organizational structures; realignment of roles and functions to promote practices that commensurate with the innovative trajectory of the organization. The type of cultural existence is important in unleashing creativity. Philippe J. et al. (2014) support this assertion and state that new thinking must align with the right cultural settings in an organization.

\section{Identify innovative leaders}

The need to identify innovative leader is espoused by Hobcraft (2015). He asserts that when employees recognize innovativeness in their leader it helps in the management of the innovation process and attracts resources to further the innovative work in the organization. Therefore, employees must be capable of identifying their innovative leaders who will provide support to the innovative process within the organization.

\section{Manage the innovation process}

The innovative process must be managed properly because there is the possibility of some of the ideas getting lost during the idea screening stage of the product development process. It is therefore material to have objectives that are well-defined with a methodical approach to managing innovation process as indicated: 
- Invite ideas from all employees within the organization especially cross-functional teams.

- Manage the screening stage effectively to elicit the best ideas.

- Institute reward systems for those whose ideas become commercialized.

- Loosing ideas must be encouraged to go through an iterative process of strategic thinking to improve on ideas or reframe new thinking and ideas.

- Organization must have a culture of organizing innovation and improvement forums where everyone is invited to suggest an innovation or improvement to identified problem.

- When ideas are commercialized it means it has been transformed from the concept stage to a product and it must be launched quickly into the market to create a competitive advantage.

- Let your new innovation leverage the organization's brand.

- Reduce cost in managing the whole process by responding quickly to issues.

- Celebrate teams' effort in any innovation success.

\section{Build capacities for innovation}

An innovative organization will always build a culture to create an environment that allows all employees to enjoy specific training pertaining to their jobs and beyond. The underlying reasons for such training are to learn improved or new methodologies on their jobs and to encourage creativity and thinking amongst employees. Another way to build capacity in the organization is by way of institutionalizing brainstorming sessions to provide innovative solutions to organizational problems.

An organization that is innovation oriented provides the financial support for innovative purposes, and this is normally captured in the annual budget. Departments like marketing and research must be resourced to carry out both internal and external research periodically on the business environment and build the culture of knowledge sharing to promote innovative practices within the organization.

\section{Empirical literature}

Empirical studies have shown a significant relationship with innovation leading to not only a firm's profitability but also a driver to increase existing market share and to enter new markets. Roberts P.W. (1999) in his study "Product Innovation, Product - Market Competition and Persistent Profitability in the US Pharmaceutical industry" finds supportive evidence of high relationship between innovative propensities and sustained profitability. That is to say, a firm that shows the ability to innovate promptly manages to sustain its profitability levels. Njagi (2016) similarly finds product innovation to have positive effects on financial performance supporting the findings of walker (2014) and Mwengi (2013); whose findings throw light on a positive relationship with product innovation and financial performance. De Faria and Mendona (2011) also affirm that product innovation has a positive effect on revenue growth, and profitability (Cozza et al. 2012) is derived from innovative practices.

Eggert et al (2014) though, makes similar findings on product innovation and its positive impact on firm's profitability; they make a significant distinction between product innovation and service innovation and stipulate that there is moderating effect on both product and service innovation type. The authors project market offering complexity to underpin the positive moderation effect of service innovation on profitability growth; while negatively impacting on the profit growth of product innovation. In other words, Eggert et al. findings suggest that service innovation can be more profitable but have unfavorable effects on product innovation profitability. Product and service innovation provides the maximum profitability, however, the success depends on the firm's ability to mitigate against the effects of complexities in the market, and the organization's capacity to manage innovation projects.

Prajogo (2016) in his study "The Relationship between Innovation and Business Performance - A Comparative Study between Manufacturing and Service Firms" finds process innovation to have a stronger relationship with business performance than product innovation. His study shows a strong relationship between process innovation and business performance in the manufacturing firms than the service firms.

Hanna (2013) affirms the relevance of people innovation. In her study "Competitive Achievement through Innovation and Knowledge" concludes that organizations see the importance to support innovative 
DOI: $10.21522 /$ TIJMG.2015.03.02.Art017

ISSN: $2520-310 \mathrm{X}$

culture; giving prominence to knowledge as a significant determinant of influencing the innovation transformation input and output. He confirms that the overall process of innovation relies on the quality of organizational human capital which supports the concept of people delivery innovation. People innovation is about investing in the human capital by releasing resources to build an effective human capital to support creativity and thinking; which has a direct positive effect on firms' performance.

Salih and Sozbilir (2013) in their study "Empirical Investigation into the Impact of Personality on Individual in the Work Place" find that individual personality dimensions are positively related to individual innovation behavior. This is supported by the works of Cameli et al. (2006) and Scot and Bruce (1994). They stipulate that innovation emanates from the ideas generated by individuals and therefore individual's behaviour towards innovation is significant to promote innovation in the organization. Managers must identify motivators and enablers of individual behaviour towards innovation to facilitate a better understanding of individual innovation behaviour. De Jong (2006) and Carmeli et al. (2006) affirm Individuals as representing the tool for generating innovation within the organizational settings.

\section{Managerial implications and business outputs}

This conceptual paper presents a strong case for a managerial focus on precise areas for innovation that will promote business growth. The 4Ds are the core determinants of business growth and encapsulate the key pillars that shape the trajectory of a business to gain a competitive advantage. The expectation of management input and the expected outcome are explained in the interventions logic below and further explicated to elicit the management implication, strategic output, and expected business growth.

Box 1. Management intervention logic for people delivery innovation

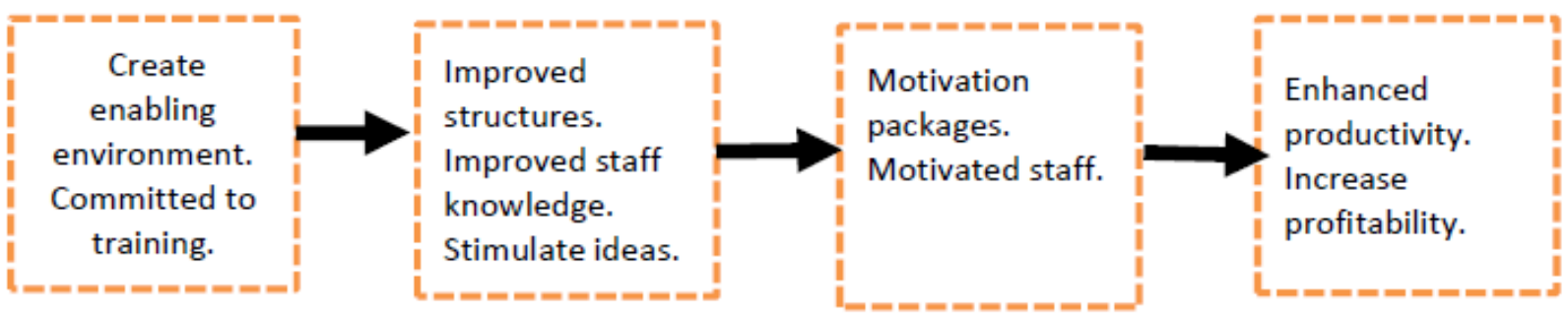

Box 2. Management intervention for product delivery

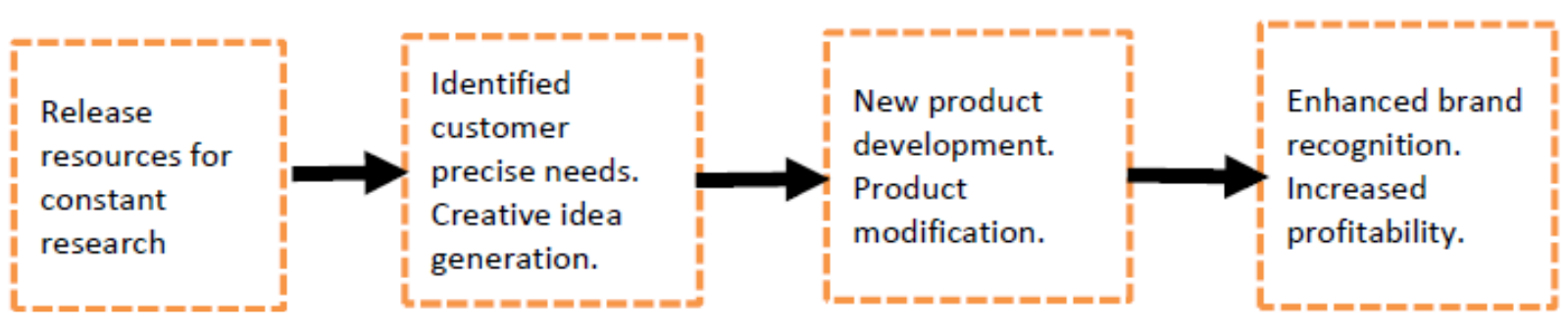

Box 3. Management intervention for process delivery innovation

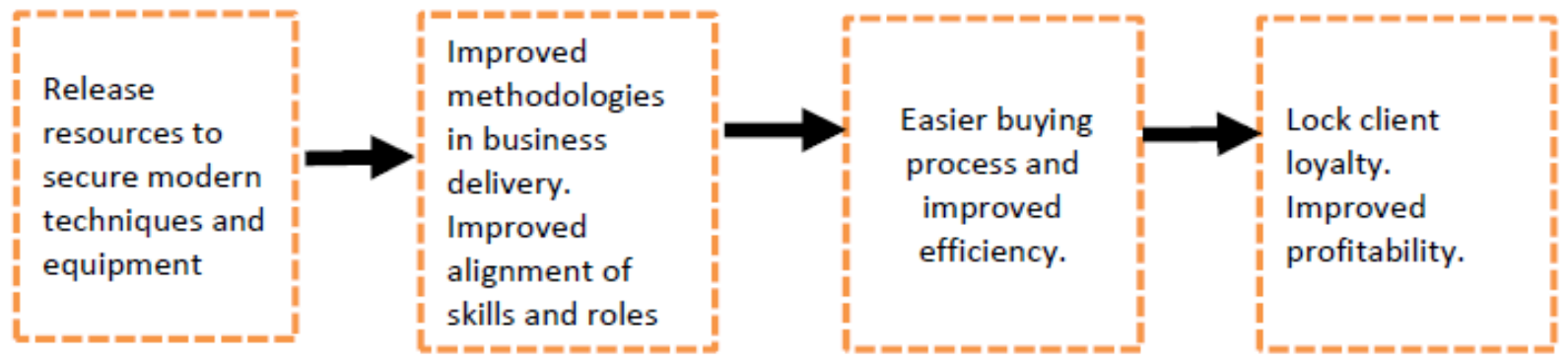

Box 4. Management intervention for service delivery innovation 


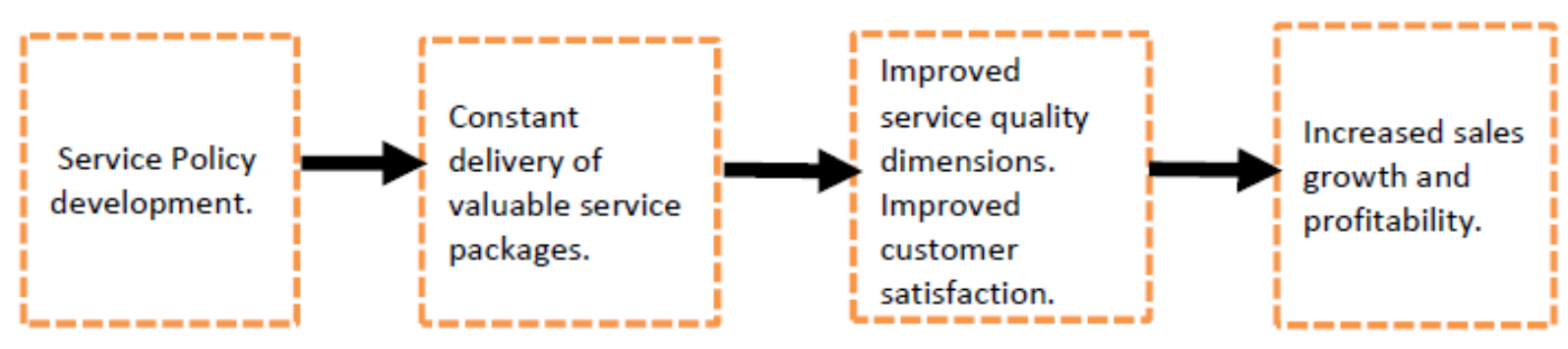

Figure 5. Management intervention logic

People are very important in every innovation process and the success of the other 3Ds reside in the people delivery innovation. The people will make things happen and therefore continuous improvement of people provokes creativity and thinking which promotes innovative activities. The knowledge of people is a strategic advantage in establishing a competitive advantage which is impossible for competitors to replicate. Employees' engagement in innovation is necessary to drive organic growth (De Faria and Mendonca 2011; Kindstroem 2010; Melton Hartline 2013) and management requirement is to be committed to training and development of its people to create a conducive environment for creativity and thinking. This must be linked with motivational packages to motivate and produce innovators to sustain and maintain business growth. The strategic outcomes of management commitment are highly skillful employees, knowledgeable staff, highly professional, a repository of ideas, motivated staff. The business output is a well-trained staff with the ability to leveraging the company's excellent core competence to build and sustain its brand identity to enhance business growth.

The product is the reason for a firm's existence and it is the only item among the 4Ds that attract economic value and therefore a firm's ability to constantly create ideas to either modify, augment or introduce a new product into the market enhances its positioning in the market and further facilitate buying for the product. What managers need to do is to release resources for continuous research to identify customer needs to reflect in new product development. A firm will be producing quality products, satisfying products and precise needs of customers. This will generate continuous usage and brand recognition culminating in increased profitability.

Process delivery innovation is to do with methods, procedures, and practices. When a firm constantly seeks new ways to improve process then it means there is creativity and thinking at work which will produce innovation. The process defines how effective the rest of the 3Ds will operate. Indeed, process delivery innovation produces effective methodologies in the business which can be possible by management release of resources to secure modern techniques and equipment. The innovative techniques will support Management to establish suitable organizational structure; alignment of skills and roles and decentralizing decision-making at the tactical levels. This allows firms to lock in client loyalty through easier buying process which will be efficient, reduce waste and characterized by promptness and accuracy to save cost. The business output is that there is improved methodologies, improved delivery systems, improved brand identity and increased profitability.

Service is everything to deliver the end product to the consumer and if this aspect is not constantly improved, the firm stands the danger of losing customers and consequently reduce sales and profitability. Service delivery innovation is the Nerve Centre of an organization without which; all other deliveries will be incapacitated if not continually innovated. Management is required to release resources for service policies development. Performance rating should be linked to customer services and establish reward systems for internal and external customers. This will improve service quality because there will be clearer communication of deliverables to increase the ability to meet client's need and to drive down cost. A welldefined service quality dimension will improve customer satisfaction, improve brand identity, and improve customer loyalty, sales growth, and increased revenues. 
DOI: $10.21522 /$ TIJMG.2015.03.02.Art017

ISSN: $2520-310 \mathrm{X}$

\section{Conclusions}

This conceptual paper presents a strong case for businesses to adopt the 4Ds of innovation in order to sustain business growth. The 4Ds of innovation - people, process, product, and service are undoubtedly the critical core areas of the business innermost workings to sustain business growth. The 4Ds rationalize the innovation process by making it simplistic and more focused; as well as touching on the strategic aspects of the business. When innovations are continuously skewed towards these four critical areas it will certainly bring change and improvement in the business without excluding any pertinent area of the business.

\section{Recommendations}

It is recommended that top management focuses on these critical areas as the most crucial elements of the business that requires constant innovation. They must be guided by the framework and the innovative matrix to facilitate innovation process in the organization.

However, this paper is a conceptual output, though, guided by various literature and deep thinking to arrive at the 4Ds of innovation; these areas are only assumed and predicted but has not been scientifically tested. One may ask open questions such as: will continuous innovation in the 4Ds impact on firm's growth? What are the relationships between the 4Ds in relation to profitability? And which of the variables has an enormous impact on business growth when new or significantly improved methods are applied? This and many more questions make it imperative for an empirical study on this subject matter. It is therefore recommended that future research must be conducted concurrently on these areas - people, process, product and service to find out if they are indeed the critical areas for continuous innovation to stimulate business growth and profitability.

\section{References}

[1]. Agbor E. (2008). Creativity and Innovation: the leadership Dynamics. JSL - Creativity and Innovation - pages 39. Journal of Strategic Leadership, Vol. IIss. 1, 2008, Pp. 39 - 45. @ 2008 School of Global Leadership and Entrepreneurship, Regent University. ISSN 1941.

[2]. Amabile T. M. (1998). How to kill creativity. Harvard Business Review. Sept - Oct 1998.

[3]. Carmeli A. et al. (2006). Self - Leadership Skills and Innovation Behavior at Work. International Journal of Manpower, 27(1), 75-90. DOI 10.1108/01437720610652853.

[4]. Charlotte Ritter (2015). Maximize Innovation while Growing Your Team. Published by Innovation Excellence. [5]. Christensen M.C. et al (1995). The Theory of Disruptive Innovation. Published by Harvard Business School. December 2015 Issue. Retrieved from: https://hbr.ot.g/2015/12/what-is-disruptive-innovation.

[6]. Dawson R. (2007). Service Delivery Innovation: Creating Client Value and Enhancement Profitability. SAPAG: The Best RVN Business Run.

[7]. De Jong, J.P.J (2016). Individual Innovation: The Connection between leadership and Employees' Innovative work behavior. Paper provided by EIM Business and Policy Research in its series. Scales Research Reports with number R2000004. Retrieved from: http://www.entrepreneurship-sme.en/pdf-ez/R200604.pdf.

[8]. Drucker P. (1954). The Practice of Management. New York Harper \& Row Publishers.

[9]. Dwyer and Mellon (1993). Product Innovation Strategies and Performance of Australian Firms. Retrieved from: https://scholar.google.com/scholar?q=9.+Dwyer+and+Mellon+(1993)

+Product+Innovation+Strategies+and+Performance+of+Australian+Firms.

[10]. Eggert et al. (2014). Product and Service Innovation on Business Profitability.

[11]. Elmansy R. (2015). Creative Diversity: Doblin's 10 Types of Innovation. Published by https://www.doblin.com/ten.

[12]. Garavan, T.N. et al. Human Capital accumulation: The role of Human resources development. Journal of European industrial Training. 25(213/4), PP 48 -68.

[13]. Hana. U (2013). Competitive Advantage Achievement through Innovation and Knowledge. Journal of Competitiveness, Zlin5.1 (Mar 2013) pages 82-96. Retrieved from: www.ejournal.cz/files/127.pdf. 
[14]. Hartog, D.N (2007). How leaders influence employees' Innovative behaviour. European Journal of Innovation management, 10(1) 41-64.

[15]. Hobcraft P. (2015). Recognizing Your Type of Innovative Leader. Published by /Innovation Excellence.com. Retrieved from: innovationexcellence.com/blog/2016/02/09.

[16]. LIopis G. (2014). 5 Ways leaders enable Innovation on their teams. Retrieved from: https://www.forbes.com/sites/glenn/loipis/2014/04//07/5-ways-leaders-enable-innovation-in-theirteams/4db48/888c4c

[17]. Moore A. G (2015). Dealing with Darwin: How Great Companies innovate at every phase of their Evolution. Published December 29th 2005 by Portfolio. Hardcover, 288 Pages. ISBN: 1591841070(ISBN13:9781591841074). Retrieved from: www.goodreads.com/books/show//29516.Dealing_with_Darwin_ [18]. Mukesh Gupta (2015). Re-framing Innovation in 2015 - How Iteration Really Does Transform Fear of failure. Published by Innovation Excellence.com.

[19]. Nanda et al. (2013). Role of Service in Customer satisfaction and Customer Loyalty: a Study on Organized retail in India. International Journal of Business Insights \& Transformation. Apr - Sept 2013, Vol.6 issue 2, P53-63.IIp. [20]. Philippe. J. et al. (2014). Innovation Governance: How Top Management Organizes and Mobilizes for Innovation.

[21]. Popa I. L et al. (2010). A Theoretical approach of the Concept of Innovation. Managerial Challenges of the Contemporary Society, 2010, Issue 1, pp. $151-156$.

[22]. Prajogo I.D. (2006). The Relationship between Innovation Performance - A Comparative Study between Manufacturing and service Firms. Knowledge and process Management, Volume 13, Issue 3. July/September 2006. Pages $218-225$.

[23]. Salih. H. \& Fikret. S. (2013). Empirical Innovation into the Impact of Personality on Individual Behaviour in the Work Place. Procedia - Social and Behavioural Science 81 (2013) 540 - 551. Retrieved from: www.sciencedirect.com.

[24]. Scott, S.G., and Bruce, R.A. (1994). Determinants of Innovative Behaviour. A Path Model of Individual Innovation in the Work Place. The Academy of Management Journal, 37 (3), 500-607.

[25]. Shipulski (2014) “To Improve Innovation, Improve Clarity” Published by Innovation Excellence.

[26]. Steiner A., Morel L., Camargo M. (2014). Well suited Organisation to Open Innovation: Empirical Evidence from an Empirical Deployment. Journal of Innovation Economic \& Management 2014/1 (no13). Pages 93-113. File URL: http://www.cairn.info/revue-journal-of-innovation-economics-2014-1-page-93.htm

[27]. Stephan Vincent (2014). Ways to Create Culture of Innovation. Published by Innovation Excellence. 